\title{
Fuzzy Expert Systems (FES) for Medical Diagnosis
}

\author{
Smita Sushil Sikchi \\ Prof. Ram Meghe Institute of \\ Technology \& Research, Badnera- \\ Amravati, India
}

\author{
Sushil Sikchi \\ Department of Radiology, \\ Punjabrao Deshmukh Memorial \\ Medical College, Amravati, India
}

\author{
Ali M. S. \\ Prof. Ram Meghe College of \\ Engineering \& Management, \\ Badnera-Amravati, India
}

\begin{abstract}
Fuzzy logic has proved to be the remarkable tool for building intelligent decision making systems based on the expert's knowledge and observations. This paper reviews the trend in development of FES and application potential over past two and half decades in the medical field, based on the references of 173 articles from 124 journals, several proceedings and web media. In order to investigate the significance of FES for medical diagnosis, the articles are classified into five distinct categories: Reviews and Surveys on Fuzzy Expert Systems in Medical Diagnosis, Applications of Fuzzy Expert Systems in Medical Diagnosis, Methodologies and Modelling of Fuzzy Expert Systems, Neuro-Fuzzy Approaches, Fuzzy Expert System Shells and Frameworks. The development of disease specific applications using FES is observed to be the area of most significant interest of the researchers. The earlier contributions are reviewed, classified, analyzed and suggested the future scope.
\end{abstract}

\section{Keywords}

Fuzzy expert systems, Medical diagnosis, Neuro-fuzzy systems, Fuzzy shells, Fuzzy frameworks

\section{INTRODUCTION}

Medical practitioners exhibit variation in decision making because of their approaches to deal with uncertainties and vagueness in the knowledge and information. The diagnostic decisions also depend upon experience, expertise and perception of the practitioner. As the complexity of system increases, it is not easy to follow a particular path of diagnosis without any mistake. Fuzzy logic presents powerful reasoning methods that can handle uncertainties and vagueness. The Fuzzy Expert Systems (FES) define imprecise knowledge and offers linguistic concept with excellent approximation to medical texts. ${ }^{1}$ Fuzzy logic is a method to render precise what is imprecise in the world of medicine. FES play an important role in medicine for symptomatic diagnostic remedies. The technocrats identified potential and possible areas for implementation of FES for medical diagnosis. Also, the efforts have been made by various researchers to establish a roadmap to forecast the future developments of expert systems in medical diagnosis. The literature published upon FES in medical diagnosis encompasses a wide spectrum including reviews, applications, innovations, conceptual studies and development of diagnostic tools. The communications between medical scientists and computer engineers have lead to an interdisciplinary advance in the development of intelligent supporting tools and systems. ${ }^{2}$ The expert systems are reported for the patient monitoring, prediction of conditions, handling of fuzzy queries in medical applications as well as evaluation and comparison of the performances with existing practices. The scope for FES has found its applications in diagnosis, differential diagnosis, therapy, image analysis, pattern recognition, patient monitoring, medical data analysis, data bank, text analysis and of theory: multi-valued logic, fuzzy relations, fuzzy set theory, fuzzy classification, etc. Past studies are contributed to the development of diagnostic techniques, quantification of medical expertise, knowledge technology transfer, identification of usage patterns and applications of FES and their adoption in practice by the medical practitioners. This paper reviews a trend in the development of FES and applications over past two decades in the medical field, on the basis of the references of 173 technical papers contributed by various researchers in 124 journals, various proceedings and web media. The articles are classified into five distinct categories: Reviews and Surveys on Fuzzy Expert Systems in Medical Diagnosis, Applications of Fuzzy Expert Systems in Medical Diagnosis, Methodologies and Modelling of Fuzzy Expert Systems, Neuro-Fuzzy Approaches, Fuzzy Expert System Shells and Frameworks. Fig.1 represents the distribution of referred reference resources.

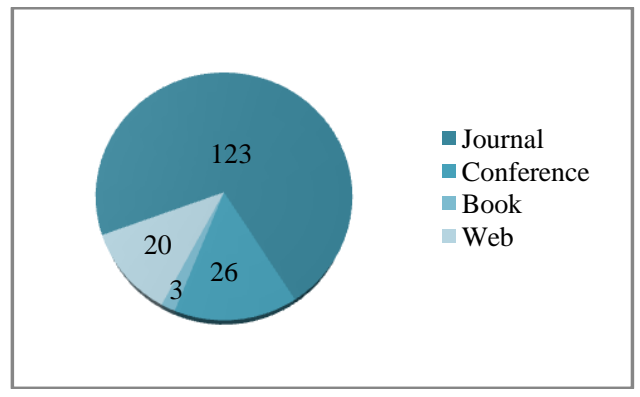

Fig 1: Distribution of reference resources

\section{REVIEWS AND SURVEYS ON FUZZY EXPERT SYSTEMS IN MEDICAL DIAGNOSIS}

The literature published by various authors under "Reviews and surveys on fuzzy expert systems in medical diagnosis" category found to be focused on the facets and modalities of experts systems pertaining to medical field. The potential and feasible areas have been identified by the researchers for implementation of fuzzy expert systems in medical diagnosis. The surveys have been presented discussing utilization of fuzzy technology and fuzzy set theory in medicine and healthcare with an analysis of its possible future developments. Broadly, the studies seem to be contributed for the development of diagnostic techniques, quantification of medical expertise and application of fuzzy expert systems with their implementation in practice. 
The survey of expert systems development using a literature review and classification of articles from 1995 to 2004 have been presented in order to explore how ES methodologies and applications have been developed during this period. $^{3}$ Medicine, often on the borderline between science and art, are an excellent exponent: vagueness, linguistic uncertainty, hesitation, measurement imprecision, natural diversity, subjectivity - all these are prominently present in medical diagnosis. ${ }^{4}$ The scope for applications in diagnosis, therapy, image analysis, pattern recognition, patient monitoring, data analysis, etc have been reviewed. ${ }^{5-8}$ The surveys are presented on utilization of fuzzy logic control and monitoring in medical fields giving an overview of fuzzy technology developments and applications in the field of medicine. The survey on several areas of utility theory and techniques of decision analysis to the design and control of computational problem solving, computer based medical diagnosis systems and artificial intelligence have been reported. ${ }^{2,9-14}$

The analysis of present review implies that, about $8 \%$ papers are contributed in conducting reviews and surveys of expert systems in medical diagnosis by various researchers.

\section{APPLICATIONS OF FUZZY EXPERT SYSTEMS IN MEDICAL DIAGNOSIS}

Human reasoning and decision making is fuzzy, involving a high degree of vagueness in evidence and concept utilization and requires a high level of uncertainty management in medical diagnosis. There are several sources of imprecision and uncertainty in an expert systems domain. The solution to problems in the domain may be imprecise. For instance, this is true of most medical problems. ${ }^{15}$ Researchers have proposed numerous innovative fuzzy expert systems to deal with vagueness and complexity and offered the practical aids to users in the form of fuzzy expert systems. Intelligent medical systems are designed with a focus on specific disease for the support of decision process. The patient monitoring, prediction of conditions, handling of fuzzy queries as well as evaluation and comparison of the performances with existing practices are also been the areas of interests of researchers. The educational tools have been developed using fuzzy logic approach to assist the users.

In the reported studies, the need, importance, potential, necessity of fuzzification and approaches for designing of medical diagnosis expert systems are discussed. ${ }^{16-20}$ Some studies have been conducted to verify the suitability of fuzzy set theory and its derived theories for developing knowledge based systems and fuzzy sets to model the medical concepts. $^{12,21,22}$ Decision support systems for diagnostic purposes of human diseases helped patients and practitioners to a great extent. ${ }^{23-29}$ Developers have extended the use of fuzzy logic theory in designing disease specific and decision theoretic expert systems for common diseases. ${ }^{30-33}$ Fuzzy approach has been explored to deal with phenomenon of vagueness in the physician's style of thinking and computer assisted expert systems for decision making. ${ }^{34-41}$ Computer assisted applications for patient's diagnosis and treatments seems to be the more recent area of interest. ${ }^{42-46}$ Web based fuzzy expert systems are reported for diagnosing human diseases. ${ }^{47-48}$ The areas in which diversified applications are developed using fuzzy logic are: fuzzy models for illness, heart and cardiovascular disease diagnosis, asthama, abdominal pain, tropical diseases, neurological diseases, medical analogy of consumption of drugs, malaria diagnosis, diagnosis and treatment of diabetes, hepatobiliary disorder, diagnosis of male impotence, syndrome differentiation, diagnosis of lung and liver diseases, prostate diseases, lymph diseases, monitoring and control in intensive care units and operation theatres, diagnosis of chronic obstructive pulmonary diseases, diagnosis of cortical malformation, etc. ${ }^{49-71,164-172}$ The non-disease areas of applications are found to be in: $\mathrm{x}$-ray mammography, interpretation of mammographic and ultrasound images, electrographic investigation of human body. ${ }^{72-74}$ The fuzzy expert system for different sounds produced by different organs in the human body using fuzzy logic toolbox of MATLAB has also been reported. ${ }^{75}$ The application of fuzzy expert system and decision tree for selection of remedy in homoeopathy is among the rare application. ${ }^{76}$ The other areas of applications of fuzzy logic are: prediction of aneurysm, fracture healing ${ }^{77,78}$ and in nonstationary FES, intuitionistic fuzzy sets. ${ }^{79,80}$

The Fuzzy Expert System has proved its usefulness significantly in the medical diagnosis for the quantitative analysis and qualitative evaluation of medical data, consequently achieving the correctness of results. The computer based diagnostic tools and knowledge base certainly helps for early diagnosis of diseases. The development of web based applications and interfaces enabled the medical practitioners to share their experiences and expertise across the world. The development of disease specific applications using FES for medical diagnosis is observed to be the area of biggest interest of the researchers reporting $44 \%$ study dedicated to it.

\section{METHODOLOGIES AND MODELLING OF FUZZY EXPERT SYSTEMS}

Researchers have suggested numerous approaches and methodologies to deal with the diversified issues pertaining to medical diagnosis. The fuzzy systems are designed for modelling the available knowledge and thinking process of medical practitioners. Novel methodologies reported by various researchers comprises their use in the development of FES for : medical knowledge acquisition, development of hybrid systems, dealing with inconsistencies, treatment planning, advisory, monitoring and control of systems, parameters predictions, artificial thinking, genetic algorithm fuzzy approach and others.

Fuzzy models are widely used for the development of decision support systems based on the expert's knowledge and observations in clinical context. The novel methodologies are presented for physician's decisions in medical informatics, medical problems solving and for the assessment of treatment planning decision process in diseases and therapies. ${ }^{81-83}$ The studies are intended to develop conceptual models of fuzzy knowledge systems. ${ }^{84}$ Problem solving algorithms are proposed for data handling, pattern recognition, fuzzy segmentation of MRI data and diagnosis of diseases using genetic algorithm fuzzy approach. ${ }^{85-90}$ As the novel approach, fuzzy logic, neural network and expert systems are combined to build hybrid systems for the diagnosis. The hybrid and intelligent systems are reported to deal with complex medical problems and diagnosis, treatment consultation and medical data classification. ${ }^{91-95}$ Researchers have addressed the issues and systems to predict the risks in terms of anticipating critical parameters for control, enhance control strategies to diagnose diseases and diagnosis regarding disorders of 
specific organs. ${ }^{96-99}$ Medical advisory systems for deciding the quantum of medicine, taking online measurements, monitoring, controlling of parameters are proposed. ${ }^{100-102}$ Computer aided medical diagnosis, medical image processing, noise reduction in medical images, simulation and automated generation of fuzzy models and expert systems using generic methodology are the areas that alleviated FES to the new height and could provide a way of generating solutions based on stored data. ${ }^{103-110}$ Medical data classification, data transformation system, feature extraction and investigation are the areas where improved performance has been reported. ${ }^{111-}$ 113 The fuzzy neural diagnostic systems are proposed by proposing novel models to combine the neural network capabilities and the fuzzy logic approach. ${ }^{114-116}$ Hamid investigated broad range of methods for incorporating multimedia expert system services in the world of heart diseases diagnosis, training and education. ${ }^{117}$

The suggested approaches and methods are successfully implemented by various researchers in the medical field. The medical practitioners and patients are using FES laden diagnostic tool with an ease and effective way. Investigation implies that, $21 \%$ papers are contributed towards the modeling and methodologies. The inclination of most of the researchers is found towards the development of fuzzy expert systems specific to expertise and problem oriented domain. It is suggested that different social science methodologies, such as psychology, cognitive science, and human behavior could implement FES as another kind of methodology. Integration of qualitative, quantitative and scientific methods and integration of FES methodologies studies may broaden the horizon of the research in medical field.

\section{NEURO-FUZZY APPROACHES}

Fuzzy logic and neural networks are complementary technologies and when brought together can provide intelligent systems. Neuro-fuzzy model incorporates the generic advantages of artificial neural networks in modeling imprecise data and qualitative knowledge as well as transmission of uncertainty. Researchers used the neuro-fuzzy approaches to build more intelligent decision making systems and presented the applications and supportive tools for the physicians.

The overviews of medical applications are presented involving neural networks and artificial intelligent techniques. ${ }^{118,119}$ The disease specific diagnostic tools and generic tools are developed using neuro-fuzzy approach. ${ }^{120,121}$ The study has been reported to improve the diagnostic accuracy of diseases. ${ }^{122}$ Neuro-fuzzy approach also has been used to derive logical inference and statistical inference for prediction or early diagnosis of diseases and risk factors. ${ }^{123-125}$ The significant studies using neuro-fuzzy approaches pertained to artificial neural network in disease diagnosis, fuzzy cluster means analysis, medical pattern classification and classifier to take some decisions are presented. ${ }^{126-130,173}$ Researchers proposed the intelligent perception-based systems, hybrid approaches for development of adaptive neuro-fuzzy inference systems and medical expert systems. ${ }^{131-}$ 133 The algorithms for Machine learning and pattern classification are proposed using neural network. ${ }^{134,135}$ Design of adaptive neuro-fuzzy systems for the detection of glaucoma, ophthalmic artery stenosis, electrocardiographic changes in patients and facial expression analysis are the applications reported using neuro-fuzzy approach. ${ }^{136-139}$
Fuzzy logic provides a high level framework for approximate reasoning that can appropriately handle both the uncertainty and imprecision in linguistic semantics, model expert heuristics and provides requisite high level organizing principles. The neural network provides self-organizing substrates for low level representation of information with online adaptation capabilities. The communications between medical scientists and computer engineers have lead to an interdisciplinary advance in the development of intelligent supporting tools and systems. The analysis implies that approximately $13 \%$ papers are contributed in the development of neuro-fuzzy based expert systems in the field of medical diagnosis.

\section{FUZZY EXPERT SYSTEM SHELLS AND FRAMEWORKS}

The expert systems are developed by many researchers using specialized software tools called "shells" and their architectures are presented. The expert system shell can hold the uncertainty properly for use in attractive domains of applications that deal with imprecise information. The expert system shells come equipped with an inference mechanism (backward chaining, forward chaining or both) and require knowledge to be entered according to a specified format. The object oriented expert system shells are also developed to link the external databases with expert systems. The literature survey reveals that, the commercially available expert system shells are rigorously used to write the application specific rule-bases. Also, the expert system shells are developed with application specific inference shells. Many authors have presented the frameworks for automatic generation of fuzzy expert systems with reference to typical diseases and decision support systems.

It has been found that the frameworks are developed for generation of a fuzzy expert systems with respect to specific diseases, general purpose diagnostic systems as well as for counseling of personal health. ${ }^{140-142}$ The architectures are proposed for the implementation and improving performance of a rule based diagnostic decision support systems related to medical diagnosis. ${ }^{143-145}$ The powerful, generic as well as hybrid expert systems for diagnosis and remodeling of existing systems are also been reported. ${ }^{146-148}$ The design of expert system frameworks for medical treatment and prevention of high risks related with the human health widened the scope for implementation of fuzzy concept in medical field. ${ }^{149}$ The studies on probabilistic interpretation and statistical analysis of medical data have been presented. ${ }^{150,151}$ Medical decision support systems are designed in the form of large scale expert system shells and used for augmenting large knowledge bases. ${ }^{152,153}$ Suitability of the computer systems using fuzzy methods and computerized monitoring and medical decision making systems have been reported. ${ }^{154-158}$ Fuzzy frameworks are also developed for the medical imaging, interface program designing and knowledge mining. ${ }^{159-161}$ The novel object oriented frameworks to construct fuzzy expert systems are proposed. ${ }^{162,163}$ The integration of two or more different knowledge representation methods has been identified as a very active research area in Artificial Intelligence.

The expert system shells and frameworks are developed and utilized so far for the tasks of quantifying medical concepts, data interpretation and constructing inferential knowledge from the knowledge bases. The generic aspects of many 
proposed fuzzy architectures enabled the automated generation of fuzzy models for mining the medical knowledge and its deployment in medical field. The analysis implies that, about $14 \%$ papers are contributed to the development of fuzzy expert system shells and frameworks in the field of medical diagnosis.

\section{TRENDS IN RESEARCH OF MEDICAL FUZZY EXPERT SYSTEMS}

The use of fuzzy logic for medical diagnosis has the history of almost three decades. Technologists and physicians have put their efforts for the exploration of "fuzzy for medical diagnosis" applicability. The study reveals that, fuzzy concept has been successfully implemented in the medical field and major quantum of the researchers' efforts, i.e. $44 \%$ contributed to development of the diversified applications. The implementation of innovative applications using fuzzy concept in medical diagnosis is the second largest area where studies are dedicated. About $40 \%$ innovative applications are found to be reported in the entire review. The share of conceptual studies and reviews and surveys are found to be $14 \%$ and $8 \%$ respectively. Fig. 2 shows the distribution of referred articles based on the major classification.

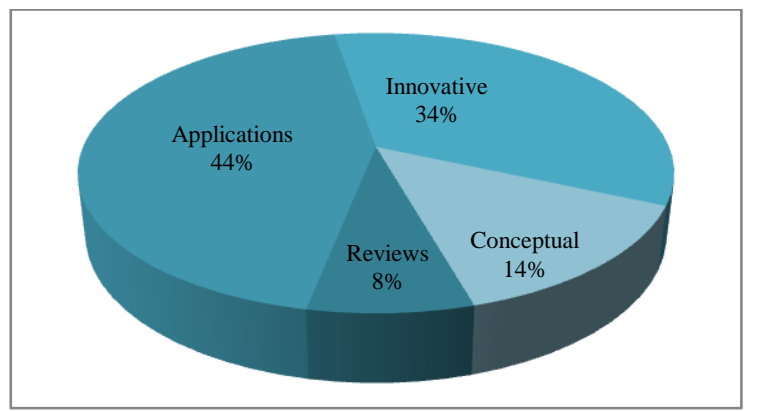

Fig 2: Distribution of articles based on major classification

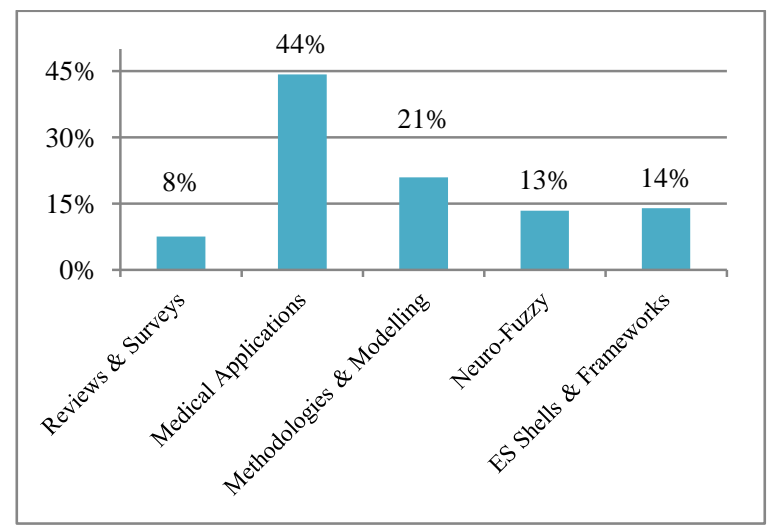

Fig 3: Percentage distribution of publications based on classification of articles

The review has been performed and articles are classified into the five distinct categories as shown in Fig. 3. It shows the percentage distribution of publications based on classification of the articles.
It has been found that, almost every aspect of the fuzzy concept had been undertaken by the researchers for their studies. To consolidate the overall idea of reported studies, it was necessary to classify the publications in some distinct categories based on the similarity of the interests of the researchers. Apart from the studies dedicated to development of diversified applications and conducting reviews and surveys, it has been notified that, $21 \%$ reported research is devoted towards the development of methodologies and models. The share of studies conducted at architectural development level of fuzzy expert system shells and frameworks have been also found to be significant, i.e. $14 \%$. The neuro-fuzzy approach has been used by many researchers and developed many fuzzy expert systems incorporating artificial intelligence to it. The investigation reveals that, $13 \%$ studies are contributed to the development of neuro-fuzzy based expert systems.

Fig. 4 shows the trend of research in medical fuzzy expert systems in last two \& half decades. The graph shows an exponential growth in the interests invested by various researchers for the inception and nourishment of fuzzy concept in the medical field. Up to the year 2000, the penetration of fuzzy concept in medical field seems to be at par. But, the recent span shows the exponential growth and more attention of researchers toward the development of fuzzy based expert systems specific to medical diagnosis. This accelerated trend intensifies the demand for more focus on the development of more intelligent medical fuzzy expert systems.

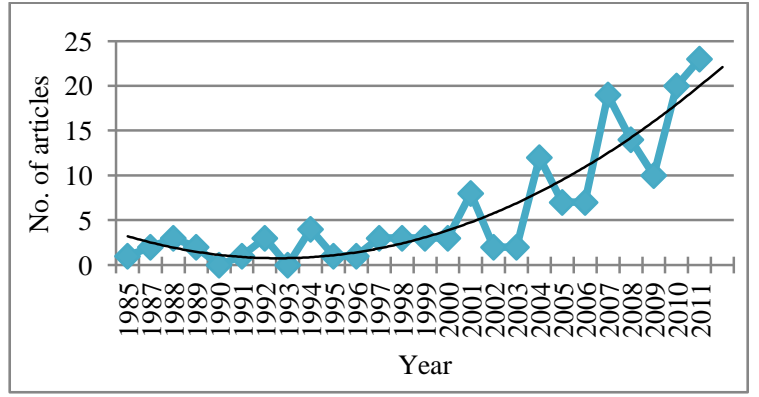

Fig 4: Trend of research in medical fuzzy expert systems in last two \& half decades

\section{FUTURE SCOPE OF FUZZY EXPERT SYSTEMS IN MEDICAL DIAGNOSIS}

The sources state that, the limitations of medical decision making systems do not result from their limited computational power, but lies in the unavailability of intellectual interface between medical practitioners and computers. Till date, almost $100 \%$ medical practitioners are using computers, but many of them still do not prefer to use the expert systems as a diagnostic aid. It proved its usefulness significantly in the medical diagnosis for quantitative analysis and qualitative evaluation of medical data, consequently achieving the correctness of results. The computer based diagnostic tools and knowledgebase certainly helps for early diagnosis of diseases. To bridge the gap, more intelligent software embedded with intelligent interfaces needs to introduce along with the expert systems. This will use the full potential of fuzzy technology in medical diagnosis segment. In future, expert systems may be developed that will understand human thinking pattern, human perceptions, gestures and human 
moods. The development of interfaces and sensory systems to acquire symptomatic parameters, their mapping and input mapping of responses of the human organs will be the potential paradigm of the research in future. Such expert systems will be termed as the third generation fuzzy expert systems. Development of the interdisciplinary and hybrid systems (third generation expert systems) seems the potential area for exploration of the concept.

\section{CONCLUSIONS}

Fuzzy Expert System technology has been growing rapidly during last three decades. The first generation expert systems have had some limitations. The focus of development of these expert systems was upon simulating the human knowledge and reasoning strategy of inference engine. The expert systems were designed for specific task and did not offer the solution for other tasks. Whereas, the second generation expert systems are generic in nature, in which common frameworks are suggested for development of the expert systems. Development of modeling methodologies, shells and frameworks are the major areas where key contributions of fuzzy technology has been observed. The initial studies on fuzzy expert systems were concerned with the concepts and representation of domain knowledge. In between the years 1990-2000, several researchers focused their attention toward the development of hybrid, fuzzy-neural expert systems and case based systems by implementing the domain knowledge. Research in the recent decade had contributed for the development of computer aided expert systems, development of multi-media based systems and suggested novel modeling approaches. The highest volume of publications on fuzzy expert systems in medical diagnosis, i.e. $62 \%$ occurred between the years 2004 to 2011. Despite enormous developments those have been taken place in the medical field, logical thinking of medical practitioners play significant role in making the diagnosis decisions. The computers and software are not capable enough to resolve entirely issues pertaining to human logical thinking and perceptions. The development of fuzzy expert systems with a blending of more intelligence, interactivity, interdisciplinary and hybrid systems are yet the potential area to explore in medical field in future and such systems will be called as the third generation expert systems.

\section{REFERENCES}

[1] Adlassnig, K.P., Fuzzy Systems In Medicine. Web URL, http://www.eusflat.org/proceedings/ EUSFLAT_ 2001/ papers/002_Adlassnig.pdf.

[2] Aruna P., Puviarasan N., Palaniappan B. 2005. An Investigation of Neuro-Fuzzy System in Psychosomatic Disorders. Expert Systems with Applications, 28: 673679.

[3] Liao, S.H. 2005. Expert System Methodologies And Applications: A Decade Review From 1995-2004. Expert Systems with Applications, 28: 93-103.

[4] Kuncheva, L.I., Steimann, F. 1999. Editorial - Fuzzy Diagnosis. Artificial Intelligence in Medicine, 16:121128.

[5] Abbod M.F., Keyserlingk D.G., Linkens D.A., Mahfouf M., 2001, Survey of Utilization of Fuzzy Technology in Medicine and Healthcare. Fuzzy Sets and Systems, 120: 331-349.
[6] Mahfouf, M. 2006. Intelligent Systems Modelling and Decision Support in Bioengineering, (Chapter 2).

[7] Phuong, N.H., Kreinovich, V., Fuzzy Logic \& its Applications in Medicine. Web URL,http:// www.cs.utep.edu / vladik/2000/tr00-36.pdf.

[8] Smith, D.E. 1992. Expert Systems for Medical Diagnosis : A Study in Technology Transfer. Technology Transfer fall, 17, 4: 45-53

[9] Mahfouf, M., Abbod, M.F., Linkens, D.A. 2001. A Survey of Fuzzy Logic Monitoring and Control Utilization in Medicine. Artificial Intelligence in Medicine, 21: 27-42.

[10] Horvitz, E. 1987. Problem-Solving Design: Reasoning About Computational Value, Tradeoffs and Resources. Proceedings of the NASA Research Forum, Mountain View, CA: 26-43.

[11] Anjaneyulu, K.S.R. 1998. Expert Systems : An Introduction. Resonance: 46-58.

[12] Adlassnig, K.P., Kolarz, G., Scheithauer, W. 1985. Present State of the Medical Expert System CADIAG-2. Methods of Information in Medicine, 24: 13-20.

[13] Linkens, D.A., Abbod, M.F., Mahfouf, M., An Initial Survey of Fuzzy Logic in Monitoring And Cotrol Utilization in Medicine. Web URL, http://citeseerx.ist.psu.edu/viewdoc/download?doi= 10.1.1.90.5177 \&rep=rep1\&type=pdf.

[14] Winkel, P. 1989. The Application of Expert Systems in the Clinical Laboratory. Clinical Chemistry, 35, 8: 15951600 .

[15] Candel, A. 1991. Fuzzy Expert Systems. CRC Press, LLC, (Chapter 1).

[16] Engle, R.L., Flehinger, B.J. 1987. Why Expert Systems for Medical Diagnosis are not being generally used: A valedictory opinion. Bulletin of the New York Academy of Medicine, 63, 2: 193-198

[17] Ali, Z., Singh, V. 2010. Potentials of Fuzzy Logic : An Approach To Handle Imprecise Data. American Medical Informatics Association, 2, 4: 358-361.

[18] Ameri, A., Moshtaghi H., Design and Development of an Expert System in Differential Diagnosis of Maxillofacial Radio-lucent Lesions. Web URL, http://www.idt.mdh.se/kurser/ct3340/archives/ht08/ papers RM08/21.pdf.

[19] Harris, G. 2006. Expert Systems - Capacity Building and Local Empowerment. Web URL, http://www.apdip.net/ apdipenote/10.pdf.

[20] Pereira, JCR, Tonelli, P.A., Barros, L.C., Ortega, N.R.S. 2002. Defuzzification in Medical Diagnosis. Advances in Logic, Artificial Intelligence \& Robotics: 202-207.

[21] Ahmad, M.R., Mahdi, A.A., Salih, A.A. 2009. Designing a Disease Diagnosis System by Using Fuzzy Set Theory. Proceedings of 5th Asian Mathematical Conference, Malaysia: 256-260.

[22] Schumann, A. 2010. Unconventional Probabilities And Fuzziness In Cadiag's Computer Assisted Medical Expert Systems. Studies in Logic, Grammer \& Rhetoric, 22, 35: 113-124. 
[23] Koschmann, T., Solomon, D., Rad, F.N., Evens, M., Weil, M.H., Rackow, E.C. Relational Storage Techniques Applied to a Medical Expert System. Web URL, $\quad$ https://e-imo.com/publications/pdfs/Rel.\%20 Storage\% 20Tech.pdf.

[24] Jeharon, H., Seagar, A., Seagar, N. 2005. Feature Extraction From Phonocardiogram For Diagnosis Based on Expert System. Int. Conf. of Proc. of IEEE Engineering in Medicine \& Biology Society, 5: 54795482 .

[25] Patra, P.S., Sahu, D.P., Mandal, I. 2010. An Expert System For Diagnosis of Human Diseases. Int. J. Of Computer Applications, 1, 13, 71-74.

[26] Bates, J.H.T., Young, M.P. 2003. Applying Fuzzy Logic to Medical Decision Making in the Intensive Care Unit. American Journal of Respiratory \& Critical Care Medicine, 167: 948-952.

[27] Saritas, I., Allahverdi, N., Sert, I.U. 2003. A Fuzzy Expert System Design for Diagnosis of Prostate Cancer. Int. Conf. on Computer Systems \& Technologies: 1-7.

[28] Spitzer, K., Thie, A., Caplan, L.R., Kunze, K. 1989. The Microstroke Expert System For Stroke Type Diagnosis. Journal of American Heart Association, 20, 10: 13531356.

[30] Torres, A., Nieto, J.J. 2006. Fuzzy Logic in Medicine and Bioinformatics. Journal of Biomedicine and Biotechnology, 2006: 1-7.

[31] Lucas, P., Knowledge Acquisition For DecisionTheoretic Expert System. Web URL, http://www.cs.ru.nl/ peterl/aisb.pdf.

[32] Biswas, D., Bairagi, S., Panse, N., Shinde, N. 2011. Disease Diagnosis System. Int. J. of Computer Science \& Informatics, I, II: 48-51

[33] Karaginnis, S.T., Dounis, A.I., Chalastras, T., Tiropanis, P., Papachristos, D. 2007. Design of Expert System For Search Allergy and Selection of the Skin Test Using CLIPS. Int. J. of Information Technology, 3, 2, 74-77.

[34] Seising, R., Schuh, C., Adlassnig, K. Medical Knowledge, Fuzzy Sets and Expert Systems. Web URL, http://cyber.felk.cvut.cz/EUNITE03 -BIO/pdf /Seising.pdf.

[35] Kiseliova, T., Moraga, C. 2005. From Sensitivity and Specificity to Confirmation and Occurrence. EUSFLAT/LFA Proc.: 898-903.

[36] Seising, R. 2006. From Vagueness in Medical Thought to the Foundations of Fuzzy Reasoning in Medial Diagnosis. Artificial Intelligence in Medicine, 38: 237256.

[37] Yuan, Y., Feldhamer, S., Gafni, A., Fyfe, F., Ludwin, D. 2002. The Development and Evaluation of a Fuzzy Logic Expert System for Renal Transplantation Assignment: Is This a Useful Tool ?. European Journal of Operation Research, 142: 152-173.

[38] Tadic, D., Cvjetkovic, V., Milovanovic, D. 2009. Determining and Monitoring of the Therapy Procedures by Application of the Artificial Intelligence Methods Relevant for Acquiring of the Quality Excellence in the Processes of the Medical Treatment. Int. J. for Quality Research, 3, 3: 1-7.
[39] Chattopadhyay, S., Pratihar, D. K., Sarkar, S.C. 2008. Developing Fuzzy Classifiers to Predict the Chance of Occurance of Adult Psychoses. Knowledge Based Systems, 21: 479-497.

[40] Liu, J.C.S., Shiffman, R.N. 1997. Operationalization of Clinical Practice Guidelines Using Fuzzy Logic. American Medical Informatics Association Inc.: 283287.

[41] Leung, K.S., Lam, W. 1988. Fuzzy Concepts in Expert Systems. IEEE, 21, 9: 43-56.

[42] Vetterlein, T., Ciabattoni, A. 2010. On the (fuzzy) Logical Content of CADIAG-2. Fuzzy Sets and Systems, 161: 1941-1958.

[43] Zahan, S. 2001. A Fuzzy Approach to ComputerAssisted Myocardial Ischemia Diagnosis. Artificial Intelligence in Medicine, 2: 271-275.

[44] Zarandi M.H.F., Zolnoori M., Moin M., Heidarnejad H. 2010. A Fuzzy Rule Based Expert System for Diagnosing Asthama. Industrial Engineering, 17, 2: 129142.

[45] Asghar, M.Z., Khan, A.R., Asghar, M.J. 2009. Computer Assisted Diagnoses For Red Eye (CADRE). Int. J. of Compouter Science \& Engineering, 1, 3: 163-170.

[46] Ahmed, A., Bigand, A., Lethuc, V., Allious, P.M. 2004 Visual Acuity of Vision Tested by Fuzzy Logic: An Application in Ophthalmology as a Step Towards a Telemedicine Project. Information Fusion, 5: 217-230.

[47] Hasan, M.A., Sher-E-Alam, K.M., Chowdhury, A.R. 2010. Human Disease Diagnosis Using a Fuzzy Expert System. Journal of Computing, 2, 6: 66-70.

[48] Djam, X.Y., Kimbi, Y.H. 2011. Fuzzy Expert System For The Management of Hypertension. The Pacific Journal of Science and Technology, 12, 1: 390-402.

[49] Holzmann, C.A., Perez, C.A., Rosselot, E. 1988. A Fuzzy Model For Medical Diagnosis. Medical Progress Through Technology, 13: 171-178.

[50] Ali, A., Mehdi, N. 2010. Fuzzy Expert System for Heart Disease Diagnosis. Proc. of Int. Multi Conference of Engineers \& Computer Scientists, I: 1-6.

[51] Neshat, M., Adeli, A. 2010. A Fuzzy Expert System For Heart Disease Diagnosis. Proc. of Int. MultiConf. of Engineers and Scientists , 1: 1-6.

[52] Zahan, S., Bogdan, R., Capalneanu, R. 2000. Fuzzy Expert System for Cardiovascular Disease Diagnosis: Tests \& Performance Evaluation, $5^{\text {th }}$ Seminar on Neural Network Applications in Electrical Engg. Ugoslavia: 6568

[53] Torbaghan, M.F., Meyer, D. 1994. MEDUSA- A Fuzzy Expert System For Medical Diagnosis of Acute Abdominal Pain. Methods of Information in Medicine, 33, 5: 522-529.

[54] Adekoya, A.F., Akinwale, A.T., Oke, O.E. 2008. A Medical Expert System For Managing Tropical Diseases. Proc. of the Third Conference on Science \& National Development: 74-86.

[55] Vaghefi, S.Y.M., Isfahani, T.M. 2009. Roses: An Expert System For Diagnosing Six Neurologic Diseases in 
Children. Int. Conf. Intelligent Systems \& Agents: 259260.

[56] Singh, M.K., Rakesh L., Ranjan A. 2010. Evaluation of the risk of Drug Addiction with the help of Fuzzy Sets. Int. J. of Research \& Reviews in Applied Sciences:,3, 2: 209-215.

[57] Oluwagbemi, O., Adeoye, E., Fatumo, S. 2009. Building a Computer-Based Expert System For Malaria Environmental Diagnosis : An Alternative Malaria Control Strategy. Egyptian Computer Science Journal, 33, 1: 55-69.

[58] Mitra, S. 1994. Fuzzy MLP Based Expert System For Medical Diagnosis. Fuzzy Set and Systems, 65 :285-296.

[59] Djam, X.Y., Kimbi, Y.H. 2011. A Decision Support System for Tuberculosis Diagnosis. The Pacific Journal of Science and Technology, 12, 2: 410-425.

[60] Filho, A.R., MDSS, Medical Diagnosis Support System. Web URL, http://www.lpa.co.uk /ftp/ribeiro. pdf.

[61] Uzoka, F.E., Osuji, J., Obot, O. 2011. Clinical DSS in the Diagnosis of Malaria :A case comparison of Two Soft Computing Methodologies. Expert Systems with Applications, $38: 1537-1553$.

[62] Koutsojannis, C., Hatzilygeroudis, I. 2004. FESMI- A Fuzzy Expert System for Diagnosis and Treatment of Male Impotence. Knowledge Based Intelligent Information \& Engg Systems, 8th Int. Conf, KES 2004, New Zealand, 3214: 1105-1113.

[63] Phuong, N.H. 1995. Fuzzy Set Theory and Medical Expert Systems :Survey and Model. 22 ${ }^{\text {nd }}$ Seminar on Current Trends in Theory and Practice of Informatics Milovy, Czech Republic, 1012: 431-436.

[64] Neshat, M., Naghibi, M.B., Esmaelzadeh, A. 2008. Fuzzy Expert System Design For Diagnosis of Liver Disorder. Int. Symposium on Knowledge Acquisition And Modelling,:252-256

[65] Huang, S.J., Shieh, J.S., Fu, M., Kao, M. 2006. Fuzzy Logic Control for Intracranial Pressure via Continuous Propofol Sedation in a Neurosurgical Intensive Care Unit. Medical Engineering and Physics, 28: 639-647.

[66] Elkfafi, M., Shieh, J.S., Linkens, D.A., Peacock, J.E. 1998. Fuzzy Logic for Auditory Evoked Response Monitoring and Control of Depth of Anaesthesia. Fuzzy Sets and Systems, 100: 29-43.

[67] Outsojannis, C., Tsimara, M., Nabil, E. 2008. HIROFILOS: A Medical Expert System for Prostate Diseases. Proc. of the 7th WSEAS Int. Conf. on Computational Intelligence, Man-Machine Systems and Cybernetics: 254-259.

[68] Polat, K., Gunes, S. 2006. Automated Identification of Diseases Related to Lymph System From Lymphograpphy Data Using Artificial Immune Recognition System with Fuzzy Resource Allocation Mechanism. Biomedical Signal Processing \& Control, 1: 253-260.

[69] Barro, S., Marin, R., Palacios, F., Ruiz, R. 2001. Fuzzy Logic in a Patient Supervision System. Artificial Intelligence in Medicine, 21:193-199.
[70] Uncu, U., Koklukaya, E., Gencsoy, A., Annadurdiyew, O. 2001. A Fuzzy Rule Based Model For Classification of Spirometric FVC Graphs in Cronical Opstructrive Pulmonary Diseases. Proc. of 23rd Annual Conf., Turkey: 1-4.

[71] Alayon, S., Robertson, R., Warfield, S.K., Alzola, J.R. 2007. A Fuzzy System for Helping Medical Diagnosis of Malformations of Cortical Development. Journal of Biomedical Informatics, 40, 3: 221-235.

[72] Kaleem, M.K. 2011. Role of Expert Systems in Digital Mammogram Processing. Int. J. of Computer Science \& Tech., 2 , 2 :96-99.

[73] Nagah, U.K., Aziz, S.A., Aziz, M.E., Murad, M., Mahdi, N.M., Shakaff, A.Y., Isa, N.A., Mashor, M.Y., Arshad, M.R. 2007. A BI-RADS Based Expert Systems For The Diagnoses of Breast Diseases. American Journal of Applied Sciences, 4, 11: 865-875.

[74] Stancovici, T.G., On An Intelligent System For Medical Diagnosis Using Electrographic Images. Web url http://www.mii.vu.lt/ADBIS/local2/Grecean. pdf.

[75] Kumar, B.H. 2007. A Fuzzy Expert System Design for Analysis of Body Sounds and Design of an Unique Electronic Stethoscope (development of HILSA kit). Biosensors and Bioelectronics, 22:1121-1125.

[76] Sadidpour, S.S., Ghidary, S.S. 2011. Remedy Selection Based of Artificial Intelligent Methods. Int. J. of Computer Applications, 19, 9: 6-9.

[77] Hatiboglu, M.A., Altunkaynak, A., Ozger, M. 2010. A Predictive Tool by Fuzzy Logic for Outcome of Patients with Intracranial Aneurysm. Expert Systems with Applications, 37:1043-1049.

[78] Ament, C., Hofer, E.P. 2000. A Fuzzy Logic Model of Fracture Healing. Journal of Biomechanics, 33: 961-968.

[79] Garibaldi, J.M., Ozen T. 2007. Uncertain Fuzzy Reasoning : A Case Study in Modeling Expert Decision Making. IEEE Transactions on Fuzzy Systems, 15, 1:1630.

[80] Szmidt, E., Kacprzyk, J. 2001. Intuitionistic Fuzzy Sets in Some Medical Applications. $5^{\text {th }}$ Int. Conf. on IFSs, 4 :58-64.

[81] Barna, I. 2007. Medical Multiagent systems. Interdisciplinarity in Engg Scientific Conf., Romania, VI-9 :1-6.

[82] Papageorgiou, E.I. 2011. A New Methodology for Decisions in Medical Informatics Using Fuzzy Cognitive Maps Based on Fuzzy Rule-Extraction Techniques, Applied Soft Computing, $11: 500-513$.

[83] Papageorgiou, E.I., Medical Decision Making Through Computational Intelligent Approaches. Web URL, http://www.debugit.eu/documents/39Papageorgiou ISMIS09.pdf

[84] Vrana, S. A. 2006. Toward Efficient Modelling of Fuzzy Expert Systems : A Survey. Agric. Econ., Czech., 52, 10: 456-460.

[85] Polat, K., Gunes, S. 2007. An Expert System Approach Based on Principal Component Analysis and Adaptive Neuro-Fuzzy Inference System to Diagnosis of Diabetes Disease. Digital Signal Processing, 17 :702-710. 
[86] Begum, S.A., Devi, O.M. 2011. Fuzzy Algorithms For Pattern Recognition In Medical Diagnosis. Assam University Journal of Science \& Technology : Physical Sciences and Technology, 7, II: 1-12.

[87] Zhang, D., Chen S. 2004. A Novel Kernelized Fuzzy Cmeans Algorithm with Application in Medical Image Segmentation. Artificial Intelligence in Medicine, 32: 3750 .

[88] Hung, W., Yang, M., Chen D., 2006. Parameter Selection for Suppressed Fuzzy C-means with an Application to MRI Segmentation. Artificial Intelligence in Medicine, $27: 424-438$

[89] Hung, W., Chen, D., Yang, M., 2011. Suppressed Fuzzysoft Learning Vector Quantization for MRI Segmentation. Artificial Intelligence in Medicine, 52, 1: $33-43$.

[90] Roychowdhury, A., Pratihar, D.K., Bose, N., Sankaranarayanan, K.P., Sudhahar, N. 2004. Diagnosis of the Diseases - Using a GA-Fuzzy Approach. Information Sciences, $162: 105-120$.

[91] Herrmann, C.S., A Hybrid Fuzzy-Neural Expert System for Diagnosis. Web URL, http://ijcai.org/ Past $\% 20$ Proceedings /IJCAI-95-VOL\%201/pdf/ 065. pdf.

[92] Koutsojannis, C., Hatzilygeroudis, I. Fuzzy Evolutionary Synergism in an Intelligent Diagnosis System. Web URL, http://citeseerx.ist. psu.edu/viewdoc/download?doi=10.1.1.143.2129 $\&$ rep=rep1\&type $=$ pdf.

[93] Brasil, L.M., Azevedo, F.M., Barreto, J.M.. 2001. Hybrid Expert System for Decision Supporting in the Medical Area: Complexity and Cognitive Computing. Int. J. of Medical Informatics, 63: 19-30.

[94] Fan, C.Y., Chang, P.C., Lin, J.J., Hsieh, J.C. 2011. A Hybrid Model Combining Case-Based Reasoning And Fuzzy Decision Tree For Medical Data Classification. Applied Soft Computing, Elsevier, 11: 632-644.

[95] Iantovics, B.L., A Novel Diagnosis System Specialized in Difficult Medical Diagnosis Problems Solving. Web URL, http://litis.univ-lehavre.fr/ bertelle/ proceedings/P09-iantovics_ epnads. pdf.

[96] Devi, N. 2010. Design Methodology of a Fuzzy Knowledgebase System to Predict the Risk of Diabetic Nephrology. Int. J. of Computer Science Issues, 7, 5: 239-247.

[97] Zarandi, M.H.F., Zarinbal, M., Izadi, M. 2011. Systematic Image Processing for Diagnosing Brain Tumors: A Type-II Fuzzy Expert System Approach. Applied Soft Computing, $11: 285-294$.

[98] Baig, F., Khan, M.S., Noor, Y., Imran, M. 2011 Design model of fuzzy logic medical diagnosis control system. Int. J. of Computer Science \& Engineering, 3, 5 : 20932108 .

[99] Guler, I., Tunca, A., Gulbandilar, E. 2008. Detection of Traumatic Brain Injuries Using Fuzzy Logic Algorithm. Expert Systems with Applications, 34: 1312-1317.

[100] Shieh, J.S., Linkens, D.A., Asbury, A.J. 2005. A Hierarchical System of On-line Advisory for Monitoring and Controlling the Depth of Anesthesia Using Self-
Organizing Fuzzy Logic. Engineering Applications of Artificial Intelligence, 18: 307-316.

[101] Grant, P. 2007. A New Approach to Diabetic Control : Fuzzy Logic And Insulin Pump Technology. Medical Engineering \& Physics, Elsevier, 29: 824-827.

[102] Lee, C.S., Wang, M.H. 2008. Ontological Fuzzy Agent for Electrocardiogram Application. Expert System with Applications, 35: 1223-1246.

[103] Hiltner, J., Fathi, M., Reusch, B. 2001. An Approach to use Linguistic and Model-Based Fuzzy Expert Knowledge for the Analysis of MRT Images. Image \& Vision Computing, 19: 195-206.

[104] Petersen, J. 1997. Similarity of Fuzzy Data in a CaseBased Fuzzy System in Anesthesia. Fuzzy Sets and Systems, 85: 247-262.

[105] Beevi, S.Z., Sathik, M.M. 2010. A Robust Segmentation Approach For Noisy Medical Images Using Fuzzy Clustering With Spatia Probability. European Journal of Scientific Research, 41, 3: 437-451.

[106] Innocent, P.R., John, R.I. 2004. Computer Aided Fuzzy Medical Diagnosis. Information Sciences, 162: 81-104.

[107] Rusnok, P., Adlassnig, K.P. 2010. Detection of Inaccuracy in a Medical Knowledge Base Using a Classical Theorem Prover. Proc. of the Conf. Health Informatics Meet Ehealth, Vienna: 1-6.

[108] Exarchos, T.P., Tsipouras, M.G., Exarchos, C.P., Papaloukas, C., Fotiadis, D.I., Michalis, L.K. 2007. A Methodology for the Automated Creation of Fuzzy Expert Systems for Ischaemic and Arrhythmic Beat Classification Based on a Set of Rules Obtained by a Decision Tree. Artificial Intelligence in Medicine, 40: 187-200.

[109] Tsipouras, M.G., Exarchos, T.P., Fotiadis, D.I. 2008. A Methodology for Automated Fuzzy Model Generation. Fuzzy Sets and Systems, 159: 3201-3220.

[110] Klinov, P., Parsia, B., Picado. D. The Consistency of the CADIAG-2 Knowledge Base : A Probabilistic Approach. Web URL, http://www.logic.at/ WWTF016/pdf/LPAR.pdf.

[111] Luukka, P. (2009). PCA for Fuzzy Data and Similarity Classifier in Building Recognition System for PostOperative Data. Expert System with Applications, 36: $1222-1228$

[112] Li, D., Liu, C., Hu S. C. 2011. A Fuzzy-Based Data Transformation for Feature Extraction to Increase Classification Performance with Small Medical Data Sets. Artificial Intelligence in Medicine, 30: $1-8$.

[113] Garibaldi, J.M., Tilbury, J., Ifeachor, E.C., The Validation of a Fuzzy Expert System for Umbilical Cord Acid-base Analysis. Web URL http://www.cs.nott.ac.uk/ jmg/papers/nnesmed-98. pdf.

[114] Ubeyli E.D. 2008. Adaptive Neuro-Fuzzy Inference System Employing Wavelet Coefficients for Detection of Ophthalmic Arterial Disorders. Expert Systems with Applications, 34: 2201-2209.

[115] Kuo, H.C., Chang, H.K., Wang, Y.Z. 2004. Symbiotic Evolution-Based Design of Fuzzy-Neural Diagnostic 
System for Common Acute Abdominal Pain. Expert Systems with Applications, 27: 391-401.

[116] Balachandran, K., Anitha, R. 2010. Study on Fuzzy and Multi layered ADALINE approach in the pre-processing of Lung Cancer Pre-Diagnosis. Int. J. of Advanced Networking \& Applications, 2, 2: 519-522.

[117] Ragab, A.H.M., Fakeeh, K.A., Roushdy, M.I. 2004. A Medical Multimedia Expert System for Heart Diseases Diagnosis \& Training. Proc. $2^{\text {nd }}$ Saudi Science Conf., Fac. Sci., KAU, IV: 31-45.

[118] Ubeyli, E.D. 2009. Adaptive Neuro-Fuzzy Inference System for Classification for ECG Signals Using Lyapunov Exponents. Computer Methods and Programs in Biomedicine, 93: 313-321.

[119] Ramesh, A.N., Kambhampati, C., Monson, J.R.T., Drew P.J. 2004. Artificial Intelligence in Medicine. The Royal College of Surgeons of England, 86 :334-338.

[120] Keles, A., Keles, A., Yavuz, U. 2011. Expert System Based on Neuro-Fuzzy Rules for Diagnosis Breast Cancer. Expert System with Applications, 38 :57195726.

[121] Eklund, P., Fuller, R. (1994). A Neuro-Fuzzy Approach to Medical Diagnosis. Fuzzy Systems \& Artificial Intelligence, $3: 53-56$.

[122] Polat, K., Sahan, S., Kodaz, H., Gunes, S. 2007. Breast Cancer and Liver Disorders Classification Using Artificial Immune Recognition System (AIRS) with Performance Evaluation by Fuzzy Resource Allocation Mechanism. Expert Systems with Applications, 32 : 173183.

[123] Dragulescu, D. 2007. Medical Predictions System. Acta Polytechnica Hungarica, 4, 3: 89-101.

[124] Chowdhury, S.R., Saha, H. 2010. Development of a FPGA Based Fuzzy Neural Network System for Early Diagnosis of Critical Health Condition of a Patient. Computers in Biology and Medicine, 40: 190-200.

[125] Balachandran, K., Anitha, R. 2010. Supervisory Expert System Approach for Pre-Diagnosis of Lung Cancer. International Journal of Advanced Engineering \& Applications: 177.

[126] Shayea, Q.K. 2011. Artificial Neural Networks in Medical Diagnosis. Int. J of Computer Science, 8, 2: 150154.

[127] Imianvan. A.A. 2011. Fuzzy Cluster Means Expert System For The Diagnosis of Tuberculosis. Global Journal of Computer Science \& Technology, 11, 6: 4048.

[128] Moein, S., Monadjemi, S.A., Moallem, P. 2008. A Novel Fuzzy-Neural Based Medical Diagnosis System. Int J. of Biological \& Life Sciences, 4, 3: 146-150.

[129] Ubeyli, E.D.. 2009. Automatic Detection of Electroencephalographic Changes Using Adaptive Neuro-Fuzzy Inference System Employing Lyapunov Exponents. Expert Systems with Applications, 36: 90319038 .

[130] Lee, J.J., Song, B.H., Kim, T.Y., Seo, D.W., Bae, S.H. (2008). A Design and Implementation of U-health Diagnosis System Using Expert System and Neural
Network. Int. J. of Future Generation Communication and Networking, 1, 1: 83-90.

[131] Rutkowska, D., Perception-Based Systems For Medical Diagnosis. Web URL, http://www.eusflat. org / proceedings /EUSFLAT_2003/ papers /1Rutkowska.pdf.

[132] Hatzilygeroudis, I., Vassilakos, P.J., Tsakalidis, A. 1997. XBONE: A Hybrid Expert System. Proc. of the Medical Informatics'97: 1-6.

[133] Nazmy, T.M., Messiry, H.E., Bokhity, B.A. 2010 Classification of Cardiac Arrhythmia Based on Hybrid System. Int. J. of Computer Applications, 2, 4: 18-23.

[134] Prasad, B.D.C.N., Prasad, P.D.S.N., Sagar, Y. 2011. An Approach To Develop Expert Systems In Medical Diagnosis Using Machine Learning Algorithms (Asthma) And A Performance Study. Int. Journal of Soft Computing, 2, 1: 26-33.

[135] Sohel, F.A., A New Neural Network with Fuzzy Technique: Disease Diagnosis, A Case Study. Web URL http://www.personal.gscit.monash. edu.au/ sohel/Papers/iccit/211_neurofuzzy.pdf.doc.

[136] Guler, I., Ubeyli, E.D. 2004. Application of Adaptive Neuro-Fuzzy Inference System for Detection of Electrocardiographic changes in Patients with Partial Epilepsy Using Feature Extraction. Expert Systems with Applications, 27: 323-330.

[137] Huang, M.L., Chen, H.Y., Huang, J.J. 2007. Glaucoma Detection Using Adaptive Neuro-Fuzzy Inference System. Expert Systems with Applications, 32: 458-468.

[138] Ramya, R., Anandanataraj, R. 2009. Application of Neuro-Fuzzy Network For The Analyzing The Pain Through Facial Expression. Int. J. of Recent Trends in Engineering, 2, 4: 8-10.

[139] Guler, I., Ubeyli, E.D. 2005, Automatic Detection of Opthalmic Artery Stenosis Using the Adaptive NeuroFuzzy Inference System, Engineering Applications of Artificial Intelligence, 18: 413-422.

[140] Tsipouras, M.G., Voglis, C., Fotiadis, D.I. 2007. A Framework for Fuzzy Expert System Creation Application to Cardiovascular Diseases. IEEE Transactions Biomedical Engg., 54, 11: 2089-2105.

[141] Binaghi, E., Gallo, I., Ghiselli, C., Levrini, L., Biondi, K. 2008. An Integrated Fuzzy Logic And Web-Based Framework For Active Protocol Support. International Journal of Medical Informatics, 77: 256-271.

[142] Snae, C., Brueckner, M. 2008. Personal Health Assistance Service Expert System. World Academy of Science, Engineering and Technology : A Biological \& Biomedical Sciences, 4, 2: 109-112.

[143] Tomar, P.P., Saxena, P.K. 2011. Architecture For Medical Diagnosis Using Rule-Based Technique. First Int. Conf. on Interdisciplinary Research \& Development, Thailand, 25: 1-25.5.

[144] Farshchi, S.M.R., Yaghoobi, M. 2011. Fuzzy Logic Expert Systems in Hospital : A Foundation View. Journal of Applied Sciences : 1-5.

[145] Lin, F., Ying, H., MacArthur, R.D., Cohn, J.A., Jones, D.B., Crane, L.R. 2007. Decision Making in Fuzzy 
Discrete Event Systems. Information Sciences, 177: 3749-3763.

[146] Chu, W.H. 1988. Generic Expert System Shell For Diagnostic Reasoning. Proc. of 1st Int. Conf. on Industrial and engineering applications of artificial intelligence \& expert systems, NY, 1: 7-12.

[147] Steimann, F., Adlassnig, K.P., Fuzzy Medical Diagnosis. Web URL, http://citeseerx.ist. psu.edu/viewdoc/download?doi=10.1.1.47.9705\&rep=re p1\&type $=$ pdf.

[148] Abraham, A., 2005. Rule-based Expert Systems, Handbook of Measuring System Design. John Wiley \& Sons: 909-919.

[149] Jung, I., Wang, G. 2007. User Pattern Learning Algorithm based MDSS (Medical Decision Support System) Framework under Ubiquitous. World Academy of Science, Engineering and Technology, 36: 184-188.

[150] Muino, D.P., A Probabilistic Interpretation of the Medical Expert System CADIAG-2. Web URL, http://www.logic.at/WWTF016/PaperCadiag2Probability .pdf.

[151] Akbarzadeh, M.R., Khorasani, M.M. 2007. A Hierarchical Fuzzy Rule-Based Approach to Aphasia Diagnosis. Journal of Biomedical Informatics, 40: 465475 .

[152] Berman, L., Cullen, M.R., Miller, P.L. 1992. Automated Integration of External Databases : A Knowledge-Based Approach to Enhancing Rule-Based Expert Systems. Proc. Annu Symp Comput Appl Med Care: 227-233.

[153] Pan, J., DeSouza, G.N., Kak, A.C. 1998. Fuzzy Shell A Large-Scale Expert System Shell Using Fuzzy Logic for Uncertainty Reasoning. IEEE Transactions on Fuzzy Systems, 6, 4: 563-68.

[154] Banerjee, A., Majumdar, A.K., Basu, A. 1994. A Fuzzy Expert System Approach Using Multiple Experts For Dynamic Follo-up of Endemic Diseases. Sadhana, India, 19, 1: 51-73.

[155] Seising, R. 2004. A History of Medical Diagnosis Using Fuzzy Relations, Fuzziness in Finland'04: 1-5.

[156] Wain, R.A., Tuhrim, S., D'Autrechy, L., Reggia, J.A. 1992. The Design and Automated Testing of an Expert System for the Differential Diagnosis of Acute Stroke. American Medical Informatics Association:94-98.

[157] Ciabattoni, A., Vetterlein, T., Adlassnig, K. 2009. A Formal Logical Framework for Cadiag-2. Studies in Health Technology \& Informatics, 150: 648-652.

[158] Boegl, K., Adlassnig, K.P., Hayashi, Y., Rothenfluh, T.E., Leitich, H. 2004. Knowledge Acquisition in the Fuzzy Knowledge Representation Framework of a Medical Consultation System. Artificial Intelligence in Medicine, 30: 1-26.

[159] Masulli, F., Schenone, A. (1999). A Fuzzy Clustering Based Segmentation System as Support to Diagnosis in Medical Imaging. Artificial Intelligence in Medicine, 16: 129-147.
[160] Isik, H., Arslan, S. 2011. The Design of Ultrasonic Therapy Device via Fuzzy Logic. Expert Systems with Applications, 38: 7342-7348.

[161] Kerdprasop, N., Kerdprasop, K. 2011. Higher Order Programming to Mine Knowledge for a Modern Medical Expert System. Int. J. of Computer Science, 8, 3, 64-72.

[162] Owaied, H.H., Qasem, M.M. 2010. Developing RuleCase-Based Shell Expert System. Proc. of Int. MultiConf. of Engineers and Scientists ,1.

[163] Qu, Y., Fu, T., Qiu, H. 2008. A Fuzzy Expert System Framework Using Object Oriented Techniques. IEEE Pacific Asia Workshop on Computational Intelligence and Industrial Applications, 2: 474-477.

[164] Badawi, A.M., Derbala, A.S., Youssef, A.M. 1999. Fuzzy Logic Algorithm for Quantitative Tissue Characterization of Diffuse Liver Diseases From Ultrasound Images. Int. J. of Medical Informatics, 55, 135-147.

[165] Saleh, A.A.E., Barakat, S.E., Awad, A.A.E. 2011. A Fuzzy Support System for Management of Breast Cancer. International Journal of Advanced Computer Science and Applications, 2, 3, 34-40.

[166] Uzoka, F.E., Obot, O., Barker, K., Osuji, J. 2010. An Experimental Comparison of Fuzzy Logic and Analytic Hierarchy Process for Medical Decision Support Systems. Computer Methods and Programs in Biomedicine, 30.

[167] Radha, R., Rajagopalan, S.P. 2007. Fuzzy Logic Approach For Diagnosis of Diabetis. Information Technology Journal, 6, 1, 96-102.

[168] Park, M., Wilson, L.S., Jin, J.S. 2000. Automatic Extraction of Lung Boundaries by a Knowledge Based Method. Conferences in Research and Practice in Information Technology, Australia, 2, 1-6.

[169] Neshat, M., Yaghobi, M., Naghibi, M.B., Esmaelzadeh, A. 2008. Fuzzy Expert System Design for Diagnosis of Liver Disorders. Int. Symposium on Knowledge Acquisition And Modelling, KAM, 252-256.

[170] Mahdi, A.A., Razali, A.M., Salih, A.A. 2011. The Diagnosis of Chicken Pox and Measles Using Fuzzy Relations. Journal of Basic \& Applied Scientific Research, 1, 7, 679-686.

[171] Koutsojannis, C., Tsimara, M., Nabil, E. 2008. HIROFILOS: A Medical Expert System for Prostate Diseases. Proc. of the 7th WSEAS Int. Conf. on Computational Intelligence, Man-Machine Systems \& Cybernetics (CIMMACS '08), 254-259.

[172] Djam, X.Y., Wajiga, G.M., Kimbi, Y.H., Blamah, N.V. 2011. A Fuzzy Expert System For The Management of Malaria. Int. J. of Pure Applied Sciences And Technology, 5, 2, 84-108.

[173] Downs, J., Harrison, R.F., Kennedy, R.L. 1996. Application of the Fuzzy ARTMAP Neural Network Model to Medical Pattern Classification Tasks. Artificial Intelligence in Medicine, 8, 403-428. 